\title{
UTILIZAÇÃO DAS INFORMAÇÕES CONTÁBEIS NA GESTÃO DAS MICROEMPRESAS COMERCIAIS
}

\section{ARTIGO ORIGINAL}

SANTANA, Leonardo Felipe Coelho ${ }^{1}$, SILVA FILHO, Marinaldo Ximendes $\mathrm{da}^{2}$, SOUSA, Leandro Galbino de ${ }^{3}$, ROCHA JUNIOR, Eder Jofre Monteiro ${ }^{4}$, ROBERTO, José Carlos Alves ${ }^{5}$, LOPES, Nelânia Ferreira ${ }^{6}$

SANTANA, Leonardo Felipe Coelho. Et al. Utilização das informações contábeis na gestão das microempresas comerciais. Revista Científica Multidisciplinar Núcleo do Conhecimento. Ano. 06, Ed. 11, Vol. 07, pp. 153-173. Novembro 2021. ISSN: 2448-0959, Link de acesso: https://www.nucleodoconhecimento.com.br/contabilidade/microempresas-comerciais, DOI: 10.32749/nucleodoconhecimento.com.br/contabilidade/microempresascomerciais

\section{RESUMO}

O presente trabalho trata-se de um estudo bibliográfico e tem como objetivo geral mostrar que a contabilidade pode fornecer ferramentas de grande relevância para as microempresas na tomada de decisão. Tendo em vista que as microempresas representam grande parte da movimentação econômica brasileira, é necessário compreender e executar os instrumentos contábeis para o seu gerenciamento e planejamento, e assegurar o retorno do capital investido a fim de manter-se no mercado. Diante disso, a questão norteadora é: Quais são as principais ferramentas contábeis voltadas para a gestão de microempresas e quais são seus benefícios

\footnotetext{
${ }^{1}$ Graduando do curso de Ciências Contábeis

${ }^{2}$ Graduando do curso de Ciências Contábeis.

${ }^{3}$ Graduando do curso de Ciências Contábeis.

${ }^{4}$ Graduando do curso de Ciências Contábeis.

${ }^{5}$ Orientador. Mestre em Engenharia de Produção. Especialista Logística Empresarial. Graduado em Administração com Ênfase em Marketing.

${ }^{6}$ Orientadora. Especialista em Auditoria Contábil, Financeira e Tributaria e Graduada em Ciências Contábeis.
}

RC: 101337

Disponível em:

https://www. nucleodoconhecimento.com.br/contabilidade/microempresas-comerciais 
para esse modelo de negócio? A fim de responder a essa questão, realizou-se uma pesquisa básica estratégica, descritiva e bibliográfica. Observou-se, neste trabalho, que a maioria dos estudos aborda as ferramentas contábeis como instrumento informacional e deliberativo, não a restringindo apenas ao planejamento fiscal. Além disso, nota-se que os estudos em geral implicam que, para que o funcionamento excelente contribua para ascensão das empresas, as ferramentas contábeis mais utilizadas, para esse modelo de gestão, são as de gestão de custos e o fluxo de caixa, voltadas a elaboração do planejamento estratégico de acordo com a necessidade do negócio, o qual auxilia a administração na tomada de decisão e assim garante a manutenção da saúde financeira da organização, levando confiabilidade nas demonstrações contábeis.

Palavras-Chave: Contabilidade, Microempresa, Gestão de empresas, Tomada de decisão.

\section{INTRODUÇÃO}

Desde os primórdios da humanidade, quando o ser humano passou a viver de forma sedentária, há a necessidade da contabilização de bens e riquezas adquiridos ao longo do desenvolvimento da sociedade. Assim, os principais conjuntos de ferramentas da contabilidade utilizáveis para o entendimento do estado desses bens e riquezas passaram a ser aprimorados desde a sua origem, sendo posteriormente aplicados em comércios, serviços, indústrias etc. (COSER, 2020).

Nesse sentido, a contabilidade tem agregado características e contribuições importantes para diferentes tipos de negócios no decorrer do desenvolvimento econômico da sociedade. Atualmente, a contabilidade possui caráter de ferramenta informacional imprescindível aos administradores em processos decisórios, com vistas na constante otimização dos lucros, tornando-se peça fundamental para qualquer empreendimento, em especial para as microempresas (IRIE e DO PRADO, 2018).

RC: 101337

Disponível em:

https://www.nucleodoconhecimento.com.br/contabilidade/microempresas-comerciais 
De acordo com Gomes et al. (2021, p. 1), a importância da contabilidade para as microempresas se dá em virtude de que "essas empresas costumam ser mais frágeis devido ao seu porte e no ambiente competitivo elas necessitam do amparo contábil para se manterem vivas devido à grande concorrência do mercado globalizado". Por essa razão, é imprescindível que os gestores, administradores, estejam conscientes das atribuições e ferramentas disponíveis na esfera da contabilidade.

Segundo os autores, é comum que os dirigentes desse tipo de empreendimento ignorem ou desconheçam os métodos contábeis, levando o seu empreendimento a situações financeiras complicadas, culminando até mesmo em falência. Fatos como esse justificam a necessidade de estudos científicos que visem discorrer sobre esse tema e agreguem soluções que mitiguem o desconhecimento sobre a funcionalidade da contabilidade, assim como de suas ferramentas aos adeptos desse modelo de empreendimento.

Diante disso, esse estudo levanta a seguinte questão norteadora: Quais são as principais ferramentas contábeis voltadas para a gestão de microempresas e seus benefícios para esse modelo de negócio?

Para responder essa pergunta, esse trabalho tem como objetivo o desenvolvimento de uma revisão da literatura sobre a definição conceitual de contabilidade voltada para a microempresa, tal como suas ferramentas e funcionalidades para essa modalidade de empreendimento.

\section{FUNDAMENTAÇÃO TEÓRICA}

Para Schiavon et al. (2015), a fundamentação teórica é um passo importante para o desenvolvimento de qualquer pesquisa, é a partir dela que serão determinadas as bases argumentativas de hipóteses ou ideias centrais de um trabalho científico. Compreender o conhecimento prévio sobre um determinado tema contribui para a 
execução adequada dos objetivos da pesquisa, mas também permite a extração de ideias para articulação de novos pensamentos e teorias.

\section{1 CONCEITO E OBJETIVO DA CONTABILIDADE}

Para Farias (2015), a contabilidade é compreendida como um conglomerado instrumental próprio para a compreensão dos fatos patrimoniais, tal quais suas modificações em resposta às decisões e ações humanas, podendo, assim, ser definida como uma disciplina do campo das ciências sociais. Para Coliath (2014), a essência da ciência social da contabilidade é reconhecível devido a influência de suas deliberações sobre a sociedade.

Segundo Mesquita (2017, p. 4) para o seu funcionamento a contabilidade "[...] se utiliza de métodos quantitativos e qualitativos, com o objetivo do estudo das variações econômico-financeiras e sociais do patrimônio das entidades". Trata-se de um grupo de valores e métodos para quem almeja o controle e a leitura adequada dos fatos ocorridos no patrimônio das entidades, e pode ser abordada em suas formas, teórica e prática (RIBEIRO, 2017).

Nesse sentido, a contabilidade teórica aborda sobre o estudo e a elaboração das regras de conduta, enquanto a prática está atrelada ao registro de operações, ao uso de ferramentas, práticas e procedimentos metodológicos da contabilidade. A contabilidade possui o objetivo de monitorar, avaliar e deliberar sobre o patrimônio (direitos e obrigações), seu objeto (OLIVEIRA e SOUZA, 2021).

O controle sobre o patrimônio deve ocorrer através de amostragem, armazenamento e processamento de dados originários dos fatos que modificam o caráter patrimonial. Sua finalidade é fornecer informações relevantes e precisas com segurança e habilidade para seus usuários, indicando a melhor decisão a ser seguida, considerando o desempenho dos desfechos financeiros das organizações, atuando como moderadora de deliberações (COSTA e SILVA, 2020). 
Outro conceito bastante útil de contabilidade é a sua interpretação como uma ciência cujo arcabouço teórico e prático pode gerar uma infinidade de ações específicas para as mais diversas situações financeiras, nas quais as entidades possam se encontrar, de acordo com Sousa e Oliveira (2019). Ainda em alinhamento com os autores, pode-se inferir como finalidade da contabilidade, catalogar e utilizar como for conveniente as informações sobre os fatos ocorrentes no patrimônio empresarial visando a orientação administrativa.

\section{1. 1 O PAPEL DO CONTADOR}

O contador é um gestor de organização que age levantando percepções sobre os aspectos empresariais e atua através delas para ajudar no ordenamento e direcionamento dos rumos de uma entidade. Para Resser e Pereira (2018, p. 276), as atuações desses sujeitos são extremamente valiosas "porque são por meio delas geradas as informações necessárias, para as mais importantes tomadas de decisões da empresa, ou seja, as que envolvem a sua saúde financeira".

Como maior agente da contabilidade, o profissional contábil tem sua principal funcionalidade atrelada ao planejamento empresarial ou ao planejamento financeiro das entidades. A atuação desse profissional perpassa por eventos como a organização do pagamento tributário, bem como a ordenação de seus direitos e obrigações, mas não deve resumir-se a isso, já que a globalização insere novas variáveis no cenário performático desse profissional como a constante inovação tecnológica que favorece o aumento instantâneo da velocidade com que a informação é difundida (SOARES, 2021).

Segundo Assis (2017), mesmo que muitas modificações e reinvenções mercadológicas tenham sido impostas pela globalização, ainda é comum encontrar alguns segmentos da economia que acredite em uma atribuição monofuncional do contador, atendendo apenas à elaboração de planos de pagamentos de impostos. Considera-se que a atribuição primordial do contador é gerar informações relevantes ao usuário da contabilidade para auxiliar na tomada de decisões. Nas palavras do 
autor sobre as atribuições do contador, afirma-se que "por meio dos seus conhecimentos e habilidades, contribui para que essas empresas tomem as decisões mais acertadas, colaborando ainda com o aumento dos lucros e da competitividade".

Por meio do entendimento gerado a partir de sua habilidade e compreensão teórica, a figura do contador deve estar entre as mais relevantes ao que concerne as deliberações sobre as políticas e planos institucionais (em especial às microempresas), assim como para identificação e reparo necessário em função das adversidades circunstanciais, através de medidas realizadas com presteza, diligência e eficiência, baseada nas informações geradas pela contabilidade. Desse modo, sua atuação transcende o monitoramento de fatos patrimoniais e da sua transformação em dados, não se limitando a sua principal função de agente informacional (SOARES, 2021).

\section{2 DEFINIÇÃO DE MICROEMPRESAS}

As microempresas podem levar prestações de serviços em diversos lugares, essa característica coloca esse modelo de negócio em posição estratégica na economia brasileira, pois satisfazem uma vasta gama de necessidades comerciais, conforme Júnior (2017). Além disso, Paz et al. (2019) argumentam que essa modalidade de empreendimento tem sido utilizada pelo governo federal como instrumento de redução da informalidade no país. Nesse sentido, o governo federal tem adotado normas de definição de microempresa para incentivar e estimular o crescimento de microempresas no Brasil.

De acordo com o previsto na lei complementar $n^{\circ}$ 123, de 14 de dezembro de 2006, no Brasil, um dos critérios mais utilizados para a definição de microempresa é o teto anual de faturamento. De acordo com esse critério, é considerado como microempresa (ME) aquela que tem um faturamento de até $R \$ 360.000,00$ ao ano (BRASIL, 2006). A ME possui ainda três modalidades: EIRELI, empresa de responsabilidade limitada; El, empresa individual; e Ltda, sociedade limitada. Tanto 
EIRELI quanto El podem ser abertos por pessoa física sem sócio. Essas duas modalidades de ME distinguem-se fundamentalmente no que tange o tratamento das dívidas em cada uma delas e no tamanho de capital necessário para a sua abertura, segundo informações do SEBRAE (2013). Paz et al. (2019) resumem essa definição elucidando que a Microempresa possui pouca complexidade em termos de alcance de produção, menor atuação de pessoas quando comparada às demais modalidade de negócio, além de "baixo volume de produção e comercialização, reduzido mercado e raio de atuação, pouco complexa, altamente centralizada com pouca estratificação e escassa divisão de tarefas e papéis e é relativamente informal".

\section{3 PRINCIPAIS FERRAMENTAS CONTÁBEIS}

Podem ser caracterizadas como ferramentas contábeis todas as abordagens que possam gerar informações estratégicas para gestão administrativa. Dentre as mais importantes encontram-se o Balanço Patrimonial e a Demonstração do Resultado do Exercício (DUMER, 2018).

\section{3. 1 BALANÇO PATRIMONIAL}

Uma ferramenta imprescindível da contabilidade para todas as modalidades empresariais é o balanço patrimonial, que consiste nos efeitos das transações e operações efetuadas pela empresa. O balanço contábil ocorre a partir de três aspectos ou grupos fundamentais: Ativo, Passivo e Patrimônio Líquido. Por Ativo se compreende os direitos e bens que são propriedade institucional. O Passivo consiste nas dívidas da empresa, assim como os reinvestimentos dos lucros na empresa, todo e qualquer capital comprometido (MARION, 2015).

O Patrimônio Líquido é onde se encontram as origens de recursos da empresa. Conforme discorre Marion (2015, p. 58), "o balanço patrimonial é o relatório mais importante, pois é através dele que se pode identificar a saúde financeira e 
econômica da empresa em determinado período, o mesmo é gerado pela contabilidade".

A partir dos grupos Ativo, Passivo e Patrimônio Líquido executa-se a apreciação do Balanço Patrimonial. Esta ação é realizada para verificação dos aspectos patrimoniais das instituições em um espaço de tempo e visa ilustrar as condições financeiras (PAZ et al., 2019).

Dentro desse espectro, cabem considerações sobre as definições de Ativo Circulante e Não Circulante, assim como as de Passivo Circulante e Passivo Não Circulante (Tabela 1). O Ativo Circulante diz respeito às contas que irão se tornar mais rapidamente em dinheiro, enquanto o Ativo Não Circulante são as contas que se transformam em dinheiro mais lentamente. O Passivo Circulante trata-se das obrigações de curto prazo da empresa, enquanto o Passivo Não Circulante consiste nas obrigações que deverão ser pagas em prazos mais longos. O Patrimônio Líquido também possui suas subdivisões em: Reserva de Capital, Reserva de Reavaliação, Reserva de Lucro, Lucros ou prejuízos acumulados, Ações em Tesouraria e Ajuste de Avaliação Patrimonial (MARION, 2015).

Tabela 1: Exemplo de demonstração de balanço patrimonial expresso em $R \$$ (real).

BALANÇO PATRIMONIAL

\begin{tabular}{|c|c|c|c|}
\hline ATIVO CIRCULANTE & $98.147,11$ & PASSIVO CIRCULANTE & $29.726,75$ \\
\hline DISPONÍVEL & $46.940,98$ & Fornecedores & $14.642,72$ \\
\hline Caixa & $10.357,29$ & Impostos a Recolher & $8.958,22$ \\
\hline Banco Conta Corrente & $36.583,69$ & $\begin{array}{l}\text { Obrigações Trabalhistas a } \\
\text { Pagar }\end{array}$ & $6.125,81$ \\
\hline VALORES A RECEBER & $51.206,13$ & NÃO CIRCULANTE & - \\
\hline Duplicatas a Receber & $43.956,22$ & & \\
\hline Estoque & $7.249,91$ & EXIGÍVEL A LONGO & - \\
\hline
\end{tabular}

RC: 101337

Disponível em:

https://www.nucleodoconhecimento.com.br/contabilidade/microempresas-comerciais 


\begin{tabular}{|c|c|c|c|}
\hline Mercadorias & & PRAZO & \\
\hline NÃO CIRCULANTE & $76.895,05$ & PATRIMÔNIO LÍQUIDO & $145.315,41$ \\
\hline & & Capital Social & $5.000,00$ \\
\hline IMOBILIZADOS & $76.895,05$ & Reserva de Lucros & - \\
\hline Imóveis & $47.546,10$ & Lucros Acumulados & $140.315,41$ \\
\hline Instalações & $9.376,41$ & & \\
\hline Maq. e Equipamentos & $7.052,57$ & & \\
\hline Móveis e Utensílios & $8.127,50$ & & \\
\hline $\begin{array}{l}\text { Computadores e } \\
\text { Periféricos }\end{array}$ & $9.060,15$ & & \\
\hline $\begin{array}{l}\text { ( - ) Depreciação } \\
\text { Acumulada }\end{array}$ & $4.267,68$ & & \\
\hline TOTAL DO ATIVO & $175.042,16$ & TOTAL DO PASSIVO & $175.042,16$ \\
\hline
\end{tabular}

Fonte: Própria (2021)

\section{3. 2 DEMONSTRAÇÃO DO RESULTADO DO EXERCÍCIO}

Padoveze (2017) elucida que a demonstração de Resultado de Exercício (DRE) deve ser considerada entre as mais relevantes demonstrações na contabilidade, pois ilustra o acúmulo de lucros ou perdas ao longo de uma linha temporal. Por essa razão, de acordo com o autor, esse é um demonstrativo extremamente importante para os gestores com grande peso de informações de capacidades deliberativas. $\mathrm{Na}$ opinião desse teórico, a principal finalidade dessa ferramenta contábil é proporcionar o resultado líquido de um exercício, avaliando-se receitas, custos e despesas, assim esclarecendo como se origina o estado líquido de uma empresa ao fim de um exercício, como demonstrado na tabela 2. Couto et al. (2018, p. 54) corroboram que "feito o estudo do balanço patrimonial, foi estruturado o DRE. A estrutura de 
resultados foi elaborada considerando as receitas [...]. Por meio da DRE apura-se o resultado da empresa, ou seja, o lucro ou prejuízo ao final do exercício"

Através da estrutura da DRE é possível analisar a situação real da empresa e, desse modo, adquirir informações contábeis e gerenciais sobre a saúde da instituição, possibilitando ao gestor capacidade de organização para somar ao planejamento estratégico da organização e no embasamento que irá auxiliar nas tomadas de decisões. Tal estrutura normatizada é prevista na Lei das Sociedades por Ações, Lei no 6.404, de 15 de dezembro de 1976, cujo disposto consiste em:

Art. 187: A demonstração do resultado do exercício discriminará: I - a receita bruta das vendas e serviços, as deduções das vendas, os abatimentos e os impostos;

II - a receita líquida das vendas e serviços, o custo das mercadorias e serviços vendidos e o lucro bruto;

III - as despesas com as vendas, as despesas financeiras, deduzidas das receitas, as despesas gerais e administrativas, e outras despesas operacionais;

IV - o lucro ou prejuízo operacional, as receitas e despesas não operacionais e o saldo da conta de correção monetária (artigo 185, § $\left.3^{\circ}\right)$;

IV - o lucro ou prejuízo operacional, as receitas e despesas não operacionais; (Redação dada pela Lei no 9.249, de 1995)

IV - o lucro ou prejuízo operacional, as outras receitas e as outras despesas; (Redação dada pela Medida Provisória nำ449, de 2008)

IV - o lucro ou prejuízo operacional, as outras receitas e as outras despesas; (Redação dada pela Lei no 11.941, de 2009)

V - o resultado do exercício antes do Imposto sobre a Renda e a provisão para o imposto;

VI - as participações de debêntures, empregados, administradores e partes beneficiárias, mesmo na forma de instrumentos financeiros, e de instituições ou fundos de assistência ou previdência de empregados, que não se caracterizem como despesa; (Redação dada pela Lei $\mathrm{n}^{0}$ 11.941, de 2009)

RC: 101337

Disponível em: 
VII - o lucro ou prejuízo líquido do exercício e o seu montante por ação do capital social (BRASIL, 1976).

Tabela 2: Exemplo de demonstração do resultado do exercício (DRE), expressa em $\mathrm{R} \$$ (real).

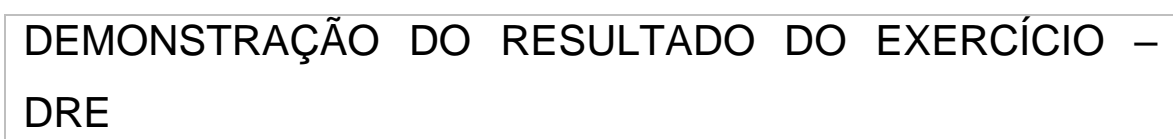

(=) RESULTADO LÍQUIDO OPERACIONAL $\mathbf{1 4 0 . 3 1 5 , 4 1}$

(=) RESULTADO LÍQUIDO DO EXERCÍCIO $\mathbf{1 4 0 . 3 1 5 , 4 1}$

Fonte: Própria (2021) 


\section{4 CONTABILIDADE VOLTADA PARA MICROEMPRESAS}

Para Gouveia (2014), a maior contribuição da contabilidade para as microempresas é uma "ferramenta dos responsáveis das empresas, particularmente na tomada de decisão. Este instrumento está por norma ao dispor dos gestores, cabendo-Ihes a escolha de utilizá-la e ponderar a sua utilidade para a decisão".

\section{4. 1 CONTABILIDADE GERENCIAL}

Para ter relevância em um mercado competitivo, os gestores devem possuir ampla visão e controle dos acontecimentos financeiros da empresa ou entidade, para isso a instituição deverá se atentar a todas as medidas apontadas pela contabilidade para beneficiar a sua administração. Desta forma, a leitura das informações contábeis facilita o entendimento da situação financeira de dado empreendimento mostrando os riscos de cada decisão. Nesse sentido, a contabilidade gerencial atua na avaliação dos processos de controle e planejamento que devem auxiliar a gestão em cada passo das decisões (DRUCKER, 2010 apud MORAIS e JUNIOR, 2019, p. 904), ou seja, a contabilidade gerencial é uma ferramenta de gestão da contabilidade da empresa que está voltada exclusivamente para subsidiar a administração empresarial (MORAIS e JÚNIOR, 2019).

\section{4. 1. 1 GESTÃO DE CUSTOS}

Dentro da contabilidade, o gerenciamento de custo é a ferramenta setorial responsável pela deliberação sobre os custos dos produtos para aquisição, venda ou construção de produtos ou o valor de serviço a ser prestado. Por meio dessa ferramenta é realizado o controle e o estabelecimento de preços e gastos com produção, garantindo a melhor demonstração dos ganhos mediante tais informações (DOCENA et al., 2019).

Lopes e Martins (2018) argumentam que o gerenciamento de custos possui atualmente duas importantes funções para a gerência, que são: o auxílio ao 
controle, assim como assistência deliberativa. Ao que concerne o controle, essa ferramenta aprovisiona informações que servirão de previsão, como o orçamento e o apontamento de possíveis problemas. Assim, no que tange a tomada de decisão, sua importância é evidenciada na necessidade de precisão de decisões na determinação de preços para que estejam alinhados aos valores praticados na praça, não cabendo erro gerencial já que o mercado é extremamente competitivo (SILVA et al., 2017).

Atrelado à contabilidade de gasto existem terminologias fundamentais para a gestão de micro e pequenas empresas tais como: gastos; investimentos; custos; despesas; perdas; pagamentos e prejuízos. Para mais detalhes sobre estas terminologias consultar Granzotto et al. (2020).

Esses autores argumentam ainda que, para as microempresas, a gestão de custo é essencial para o seu funcionamento em todos os seus aspectos, pois é a partir dela que serão definidos os preços dos produtos, das terceirizações e serviços, políticas de descontos etc. Nesse sentido, decisões incorretas podem custar o funcionamento da microempresa, por isso a demanda das empresas por precisão nas informações como retorno de investimento e lucratividade é crescente.

\section{4. 1. 2 GESTÃO FINANCEIRA}

Gestão financeira pode ser compreendida como o conjunto de processos, ações e métodos que possibilitam o controle, a análise e o planejamento das ações financeiras institucionais. Ou seja, consiste no montante de medidas a serem tomadas para o aumento dos lucros e consequente crescimento empresarial.

Nesse sentido, Gomes et al. (2014) propõe que a gestão de aspectos financeiros empresariais seja realizados com a utilização de tais indicadores como: controle das finanças e fluxo de caixa. O modelo segundo essas características favorece o ajuste de desordem financeira por intermédio de diagnóstico ou descoberta de sintomas, e mitigação de seus agentes causadores que compreendem respectivamente 
"indisponibilidade crônica de caixa e captação repetitiva de recursos através de empréstimos, excesso de estoques, prazo máximo de recebimento maior que prazo médio de pagamento e excesso de imobilizações", com isso, cabe ao gestor financeiro a realização dessas ações.

O gestor financeiro gera subsídios para os traços de metas e objetivos que garantirão autonomia deliberativa e fundamentos basais para o controle financeiro e planejamento das instituições. Esse é um dos marcos que fundamentam as microempresas em buscas constantes por atualização de tendências e inovação, gerando crescimento e aumentando a sua competitividade. Dito isto, o administrador financeiro deve atuar para que o capital desejado esteja disponível quando necessário, assistindo o investimento e redução de riscos no valor estimado e com um custo menor (SALAI e TRETER, 2015).

Salai e Treter (2015, p. 3) afirmam ainda que a manutenção do funcionamento e o sucesso das finanças, em especial das microempresas, dependem em grande parte das estratégias traçadas e das decisões que ocorrem a partir do planejamento financeiro, e que essa etapa é provavelmente crucial em cenários econômicos conturbados e voláteis como no caso da economia brasileira. Segundo esses autores, "o planejamento financeiro assume um papel estratégico e importante no sentido de buscar uma previsão de indicadores de desempenho como: liquidez, endividamento e lucratividade e conforme o ramo de atividade". Para a realização efetiva dessa ferramenta é crucial que se aplique o monitoramento do fluxo de caixa que dará origem às primeiras informações para as decisões administrativas e gerenciais (SILVA et al., 2020).

\section{4. 1. 3 FLUXO DE CAIXA}

Através do fluxo de caixa os gestores podem comprovar os fatos financeiros adquiridos pelas empresas ou entidades que darão suporte decisório aos administradores quanto aos rumos institucionais. Também pode ser considerada como a ferramenta que associa ingressos e desembolsos empresariais ao longo de 
uma linha temporal. Desse modo, atua como peça estrutural da instituição, concedendo a compreensão de quando os recursos são satisfatórios no apoio às operações (ARAÚJO et al., 2015). Barros et al. (2021) destacam a importância do fluxo de caixa para os gestores "em se tratando de gerenciamento financeiro, principalmente das pequenas empresas, pois demonstra de forma simples e clara os movimentos de entradas e saídas de valores monetários no caixa em um determinado período", ou seja, o fluxo de caixa é o mecanismo pelo qual as empresas controlam o seu capital de giro. Como demonstrado na tabela 3.

Seguindo esta premissa, compreende-se que o planejamento de fluxo de caixa é um processo cuja finalidade é dar subsídio às deliberações gerenciais contribuindo para que a entidade desempenhe melhor controle sobre seus aspectos financeiros e estratégicos. Sendo assim, a gestão no planejamento de fluxo de caixa atua para as microempresas como relevante assistente de práticas ideais do controle das finanças. (ARAÚJO et al., 2015; BARROS et al., 2021).

Tabela 3: Exemplo do controle de fluxo de caixa, demonstrado em $\mathrm{R} \$$ as receitas e despesas de uma empresa.

\begin{tabular}{|c|c|c|c|c|c|c|}
\hline \multicolumn{7}{|l|}{ Receitas 2020/01 } \\
\hline \multirow[b]{2}{*}{ DESCRIÇÃO } & \multicolumn{2}{|c|}{ Janeiro } & \multicolumn{2}{|c|}{ Fevereiro } & \multicolumn{2}{|l|}{ Março } \\
\hline & $\begin{array}{l}\text { Previs } \\
\text { to }\end{array}$ & Realizado & $\begin{array}{l}\text { Previs } \\
\text { to }\end{array}$ & Realizado & $\begin{array}{l}\text { Previs } \\
\text { to }\end{array}$ & $\begin{array}{l}\text { Realiza } \\
\text { do }\end{array}$ \\
\hline $\begin{array}{ll}\text { Vendas } & \text { de } \\
\text { Mercadorias } & \end{array}$ & $\begin{array}{l}2.000 \\
00\end{array}$ & $1.900,00$ & $\begin{array}{l}2.000 \\
00\end{array}$ & $1.780,00$ & $\begin{array}{l}2.000 \\
00\end{array}$ & $\begin{array}{l}2.015,0 \\
0\end{array}$ \\
\hline $\begin{array}{l}\text { Prestação de } \\
\text { Serviços }\end{array}$ & $\begin{array}{l}3.000 \\
00\end{array}$ & $2.300,00$ & $\begin{array}{l}3.000 \\
00\end{array}$ & $2.443,45$ & $\begin{array}{l}3.000 \\
00\end{array}$ & $\begin{array}{l}2.988,0 \\
0\end{array}$ \\
\hline Outras rendas & $\begin{array}{l}1.000 \\
00\end{array}$ & $1.200,00$ & $\begin{array}{l}1.000 \\
00\end{array}$ & 750,00 & $\begin{array}{l}1.000 \\
00\end{array}$ & 798,00 \\
\hline Empréstimo & - & - & - & - & - & - \\
\hline Receita total & 6.000 & $5.400,00$ & 6.000 & $4.973,45$ & 6.000 & $5.801,0$ \\
\hline
\end{tabular}

RC: 101337

Disponível em:

https://www.nucleodoconhecimento.com.br/contabilidade/microempresas-comerciais 
00

Despesas 2010

Despesas 2020/01

\begin{tabular}{|c|c|c|c|c|c|c|}
\hline \multirow[b]{2}{*}{ DESCRIÇÃO } & \multicolumn{2}{|l|}{ Janeiro } & \multicolumn{2}{|l|}{ Fevereiro } & \multicolumn{2}{|l|}{ Março } \\
\hline & $\begin{array}{l}\text { Previs } \\
\text { to }\end{array}$ & $\begin{array}{l}\text { Realiza } \\
\text { do }\end{array}$ & Previsto & $\begin{array}{l}\text { Realiza } \\
\text { do }\end{array}$ & Previsto & $\begin{array}{l}\text { Realiza } \\
\text { do }\end{array}$ \\
\hline Aluguel & 800,00 & 800,00 & 800,00 & 800,00 & 800,00 & 800,00 \\
\hline Conta de luz & 300,00 & 270,00 & 300,00 & 210,00 & 300,00 & 255,00 \\
\hline Conta de água & 60,00 & 50,00 & 60,00 & 43,00 & 60,00 & 40,00 \\
\hline Gás & 60,00 & - & 60,00 & - & 60,00 & - \\
\hline IPTU & - & - & - & - & 75,00 & 75,00 \\
\hline $\begin{array}{l}\text { Telefone } \\
\text { comercial//nternet }\end{array}$ & 100,00 & 100,00 & 100,00 & 99,00 & 100,00 & 100,00 \\
\hline Contabilidade & 500,00 & 500,00 & 500,00 & 500,00 & 500,00 & 500,00 \\
\hline $\begin{array}{l}\text { Consertos/manute } \\
\text { nção }\end{array}$ & - & - & - & - & - & - \\
\hline Fornecedores & $\begin{array}{l}1.450 \\
00\end{array}$ & $\begin{array}{l}1.450,0 \\
0\end{array}$ & $1.500,00$ & $\begin{array}{l}1.500,0 \\
0\end{array}$ & $1.500,00$ & $\begin{array}{l}1.650,0 \\
0\end{array}$ \\
\hline Alimentação & 300,00 & 250,00 & 300,00 & 250,00 & 300,00 & 200,00 \\
\hline Transporte & 450,00 & 500,00 & 450,00 & 500,00 & 450,00 & 300,00 \\
\hline Plano de saúde & 145,00 & 145,00 & 145,00 & 145,00 & 145,00 & 145,00 \\
\hline Outros gastos & - & - & - & - & - & - \\
\hline Despesa total & $\begin{array}{l}4.165 \\
00\end{array}$ & $\begin{array}{l}4.065,0 \\
0\end{array}$ & $4.215,00$ & $\begin{array}{l}4.047,0 \\
0\end{array}$ & $4.290,00$ & $\begin{array}{l}4.065,0 \\
0\end{array}$ \\
\hline LUCRO/PREJUÍZO & $1.335,0$ & & 926,45 & & $1.736,00$ & \\
\hline
\end{tabular}

Fonte: Própria (2021)
00

00

0 


\section{5 EMPRESAS COMERCIAIS}

Um aspecto importante para a definição de empresa comercial é que suas atividades não compreendem processos de produção, mantendo-se estritamente a atuação de comércio. Além disso, entidades enquadradas nessa modalidade possuem vínculo de troca comercial em via direta com o consumidor como, tal qual, nas interações de varejo, podendo também adquirir os bens com o produtor e negociá-los com profissionais do varejo, como ocorre na modalidade de varejo (SEBRAE, 2019).

\section{5. 1 TIPO DE GESTÃO NAS EMPRESAS COMERCIAIS}

A gestão comercial engloba as mais diversas estratégias de condução das tratativas de negócio a partir de uma série de processos cruciais para o funcionamento do corpo empresarial. As adequações e tomadas de decisões assertivas específicas necessárias para cada setor são passos importantes para um andamento bemsucedido. Dentre os processos organizacionais vitais para o funcionamento das instituições encontra-se, a gestão de finanças; gerenciamento de recursos humanos; gestão dos estoques ou materiais; e primordialmente o planejamento estratégico (TACHIZAWA, 2015).

O gerenciamento do desenvolvimento de indivíduos colaboradores é o principal foco da gestão de pessoas em uma instituição para assegurar engajamento e organização de pessoal e suas atribuições para o funcionamento dinâmico e fluido de qualquer entidade ou instituição empresarial. Para alcançar essa meta os modelos adotados na gestão de pessoal devem levar em consideração as características inatas do ser humano e garantir capacitação da mão de obra de acordo com as peculiaridades da empresa para assim assegurar seu espaço no mercado com desempenho competitivo frente aos concorrentes (ALAJA e GIORDANI, 2018) 
Para uma gestão empresarial bem-sucedida a gestão de estoque deve estar entre as ações prioritárias nos planos operacionais de qualquer entidade com tais fins, sobretudo das microempresas, pois seu conhecimento circunstancial preciso garante decisões administrativas mais assertivas, bem como a melhor logística de organização de produtos para o melhor funcionamento da instituição. Nesse sentido, uma ótima gestão estratégica dos estoques pode implicar diretamente no crescimento dos lucros empresariais (PAOLESCHI, 2014).

A otimização produtiva de empresas em função de um gerenciamento adequado do estoque pode assegurar um salto de qualidade e desenvolvimento, pois, segundo Cruz e Almeida (2021, p. 15) a de "percepções no arranjo físico [...], como a inutilização ou utilização inadequada dos espaços, se propõem melhorias para possibilitar o processo operacional mais produtivo".

O direcionamento de todas as ferramentas de gerenciamento de cada setor de uma empresa geralmente é determinado no planejamento estratégico. É por isso que o planejamento estratégico deve ser tratado como acontecimento crucial, pois a dinâmica de funcionamento a partir da essência, propósito e diagnósticos de cada setor com as prováveis decisões mais relevantes será traçada em um importante marco do curso para o futuro da instituição (POSSAMAI, 2014).

\section{PROCEDIMENTOS METODOLÓGICOS}

Procedimentos metodológicos são etapas ou passos ordenados para satisfazer determinado rigor científico, visando à investigação de um problema ou fenômeno, no âmbito de uma ciência para atingir uma finalidade, de acordo com Aragão e Mendes Neta (2017). Para Pereira et al. (2018), procedimentos metodológicos consistem em conjuntos de saberes dedicados à normatização do trabalho científico de acordo com a sua finalidade. 


\subsection{QUANTO À NATUREZA DA PESQUISA}

Ao que concerne a sua natureza ou tipo, pode-se compreender a pesquisa como sendo básica ou aplicada. Na pesquisa básica busca-se o aprofundamento do conhecimento disponível em determinada ciência, visa a preencher lacunas sobre assuntos ainda não completamente abordados, a qual geralmente abrange textos caracterizados por análises conceituais, descrições ou sistematização de ideias. Em geral, essas pesquisas podem ser puras ou estratégicas (NASCIMENTO, 2016).

A pesquisa aplicada visa à solução de problemas na prática, criando, estendendo, ou redefinindo conhecimento para as soluções reais. Resumidamente, o objetivo desse tipo de pesquisa é desenvolver soluções práticas a partir de conhecimentos científicos (FLEURY e WERLANG, 2016).

Com base nessas premissas, uma vez que o presente estudo visa ao aprofundamento e discussão a respeito das ferramentas contábeis na gestão de microempresas, acredita-se que o mesmo possa ser compreendido como um estudo no âmbito da pesquisa básica. Porém, como se trata de um estudo que visa a discutir conceitos já existentes, agregando-lhes interpretações que talvez possam ser de alguma forma utilizadas como, por exemplo, no auxílio de gestores ou estudantes, é adequado o seu enquadramento como uma pesquisa básica estratégica.

\subsection{QUANTO AOS FINS}

Libório e Terra (2015) explicam que a pesquisa científica também pode ser abordada de acordo com seus fins ou objetivos. Nesse caso, caracteriza-se por ser exploratória, descritiva ou explicativa. A pesquisa exploratória mantém em vista a questão problema, podendo haver o levantamento de hipóteses. Pode abranger entrevistas, levantamento de dados, ou revisão bibliográfica. 
A pesquisa descritiva enaltece as associações entre grupos amostrais variáveis ou eventos, fazendo-se uso geralmente de descrições fenomenológicas e questionários para o levantamento de informações. Por fim, a pesquisa explicativa almeja o esclarecimento dos fatos, bem como seus fatores causais (NUNES et al., 2016).

Neste estudo teve-se a finalidade de realização de uma revisão de literatura sobre as principais ferramentas contábeis utilizadas para a gestão de microempresas. Tendo em vista a compreensão de ser uma pesquisa científica em virtude de seus objetivos demonstrada por Libório e Terra (2015), o presente estudo enquadra-se no contexto de uma pesquisa descritiva.

\subsection{QUANTO AOS MEIOS}

Outro aspecto importante pelo qual uma pesquisa científica pode ser observada diz respeito aos meios utilizados para obtenção de dados ou informações, quanto ao modo pretendido de investigação. Menezes et al. (2019) descrevem dois tipos de delineamentos metodológicos, os que são obtidos de fontes escritas, impressas ou publicadas e aqueles fornecidos por pessoas.

Zanella (2013) demonstra que na categoria de delineamento metodológico cujo material é obtido por meios textuais publicados ou não, se enquadram as pesquisas bibliográficas e as pesquisas documentais. Dentre outras modalidades de pesquisa encontram-se: experimental; levantamento; estudo de coorte; estudo de caso e etc.

Por se tratar de um estudo cujas fontes de informação consistem em materiais publicados em periódicos ou repositórios institucionais, como artigos, dissertações e outros trabalhos de conclusão de curso, o presente trabalho pode ser compreendido no âmbito de uma pesquisa bibliográfica. A janela temporal em que as buscas deste estudo foram realizadas compreende os anos entre 2014 e 2021. 


\section{CONSIDERAÇÕES FINAIS}

Essa pesquisa se propôs, com o objetivo, o desenvolvimento de uma revisão da literatura sobre a definição conceitual de contabilidade voltada para a microempresa, tal como suas ferramentas e funcionalidades para essa modalidade de empreendimento; Com base nisso, é possível assumir que o objetivo do estudo foi alcançado, visto que discutiu-se a funcionalidade das ferramentas contábeis para a gestão de microempresas, tendo como questão norteadora: Quais são as principais ferramentas contábeis voltadas para a gestão de microempresas e seus benefícios para esse modelo de negócio? Com base no material disponível na literatura foi demonstrado, nesse estudo, a definição e a aplicabilidade de conceitos e ferramentas contábeis, assim como o papel da contabilidade como ciência social e um grande instrumento para auxiliar os gestores na tomada de decisão das microempresas.

Entretanto, é amplamente conhecido que sobre a questão são cabíveis debates, principalmente no que diz respeito de como estas ferramentas podem melhorar o desempenho, o desenvolvimento e garantir a sobrevivência das microempresas. Neste estudo, investigou-se o uso das principais ferramentas da contabilidade utilizadas para a gestão de microempresas, e para isso foi realizado uma revisão de literatura sobre o tema no contexto brasileiro.

Nesse sentido, analisou-se como a utilização de abordagens para levantamento e gerenciamento de informações, a função do profissional contábil, a utilização balanço patrimonial, a demonstração de exercício, a contabilidade gerencial, a gestão de custo, a gestão financeira e o fluxo de caixa e planejamento estratégico contribuem para o desempenho dos gestores de microempresas.

Observou-se, neste trabalho, que a maioria dos estudos aborda as ferramentas contábeis como instrumento informacional e deliberativo, não a restringindo apenas ao planejamento fiscal. Além disso, nota-se que os estudos em geral implicam que, para que o funcionamento excelente contribua também para ascensão das 
empresas, as ferramentas contábeis mais utilizadas para esse modelo de gestão são as de gestão de custos e o fluxo de caixa, voltadas a elaboração do planejamento estratégico de acordo com a necessidade do negócio, o qual auxilia a administração na tomada de decisão e assim garante a manutenção da saúde financeira da organização, levando confiabilidade nas demonstrações contábeis.

Conclui-se que a aplicabilidade da contabilidade nas microempresas é de grande relevância, pois ela apresenta aos gestores importantes ferramentas para o bom funcionamento, de modo a auxiliar na tomada de decisão.

Sugere-se que em futuras pesquisas a respeito desse tema sejam elaborados comparativos como o cenário de outros países para se verificar semelhanças, diferenças e diferenciais da contabilidade das microempresas brasileiras para agregar novas perspectivas e contribuir com o conhecimento internacional.

\section{REFERÊNCIAS}

AJALA, R. S.; GIORDANI, R. Proposta de gestão de estoques para atacado: um estudo de caso. Revista Latino-Americana de Inovação e Engenharia de Produção, v. 6, n. 9 , p. 40-60, 2018.

ARAGÃO, J. W. N.; NETA, M. A. H. M. Metodologia científica. 1 ed. Salvador: UFBA, Faculdade de Educação, Superintendência de Educação a Distância, 2017. $51 \mathrm{p}$.

ARAÚJO, A. et al. A Importância da gestão no planejamento de fluxo de caixa para o controle financeiro de micro e pequenas empresas. REDECA, São Paulo, v. 2, ed. 2, p. 73-88, 2015.

BARROS, R. R. et al. Demonstração do fluxo de caixa: sua importância na gestão de uma microempresa. Brazilian Journal of Development, v. 7, n. 3, p. 31894-31905, 2021. 
BRASIL. Lei no 6.404, de 15 de dezembro de 1976. Brasília, 1976. Disponível em: http://www.planalto.gov.br/ccivil_03/leis//6404consol.htm. Acesso em: 03 set. 2021.

BRASIL. Lei Complementar 123, de 14 de dezembro de 2006. Institui o Estatuto Nacional da Microempresa e da Empresa de Pequeno Porte. Diário Oficial da União. Brasília, 2006. Disponível em: http://www.planalto.gov.br/ccivil_03/leis/lcp/lcp123.htm. Acesso em: 03 set. 2021.

COLIATH, G. C. A contabilidade como ciência social e sua contribuição para o capitalismo. Revista ENIAC Pesquisa, v. 3, n. 2, p. 152-161, 2014.

COSER, T. Contabilidade de gestão em sintonia com o Business Intelligence (BI): estudo de caso. Brazilian Journal of Business, v. 2, n. 3, p. 3093-3112, 2020.

COUTO, M. J. et al. Análise econômico-financeira da produção leiteira: um estudo de caso no Centro-Oeste mineiro. Extensão Rural, v. 25, n. 1, p. 41-59, 2018.

DA PAZ, W. T. B. et al. A utilização das ferramentas contábeis gerenciais na tomada de decisão nas microempresas do município de Praia Norte/TO. Humanidades \& Inovação, v. 6, n. 12, p. 146-158, 2019.

DE ASSIS, W. M. B. Planejamento tributário: um estudo sobre o papel do contador na visão dos gestores das micro e pequenas empresas. Revista de Empreendedorismo e Gestão de Micro e Pequenas Empresas, v. 2, n. 01, p. 162176, 2017.

DO NASCIMENTO, F. P. Classificação da Pesquisa: Natureza, método ou abordagem metodológica, objetivos e procedimentos. Brasília: Thesaurus, 2016.

DOCENA, D. R. et al. Contabilidade de custos: uma ferramenta para gestão empresarial. Revista Eletrônica de Ciências Sociais Aplicadas. ISSN 2176-5766, v. 6, n. 2, p. 119-143, 2019. 
DUMER, M. C. R. Importância e utilização da contabilidade de custos nas micro e pequenas empresas: uma análise comparativa com outras ferramentas contábeis pela matriz de Slack. Revista de Gestão e Contabilidade da UFPI, v. 5, n. 2, p. 147-165, 2018.

FARIAS, M. R. S.; MARTINS, G. A. Contabilidade como ramo de conhecimento: Ciência, tecnologia e prática. Revista Universo Contábil, v. 11, n. 3, p. 27-42, 2015.

FLEURY, M. T. L.; DA COSTA WERLANG, S. R. Pesquisa aplicada: conceitos e abordagens. Anuário de Pesquisa GVPesquisa, 2016.

FRISKE, H. L; SOARES, A. C. B. S. Gestão financeira através do fluxo de caixa: estudo de geração de dados para tomada de decisões em propriedades rurais. Revista de psicologia, v. 15, n. 54, p. 134-149, 2021.

GOMES, A. J. A. et al. Contabilidade gerencial: a importância das ferramentas gerenciais contábeis nas microempresas. Brazilian Journal of Development, v. 7, n. 6 , p. 58937-58956, 2021.

GOUVEIA, H. M. N. A utilidade da contabilidade para as microempresas. Universidade do Algarve, Faro, 2014.

GRANZOTTO, A.; DE GREGORI, R. Gestão de custos: uma ferramenta eficiente nas tomadas de decisão nas micro e pequenas empresas. Anais do Congresso Brasileiro de Custos - ABC, [S. I.], Disponível em: https://anaiscbc.emnuvens.com.br/anais/article/view/4009. Acesso em: 13 set. 2021.

IRIE, L.; DO PRADO, E. V. Contabilidade gerencial como instrumento de tomada de decisão: um estudo de caso em uma microempresa em Mogi Guaçu-SP. Universitas, n. 23, 2018. 
JÚNIOR, L.; EVERTON, H. Aplicação do Lean Office na gestão do tempo do processo de licitação de obras públicas na Universidade de Brasília. Departamento de Engenharia Civil e Ambiental, Universidade de Brasília, 2017.

LIBÓRIO, D.; TERRA, L. Metodologia científica. São Paulo: Editora Laureate International Universities, 2015.

LOPES, A. C. V.; MARTINS, L. A. Gestão de custos nas micro e pequenas indústrias do setor de confecções da cidade Dourados/MS. In: Anais do Congresso Brasileiro de Custos-ABC. 2018.

MARION, J. C. Contabilidade empresarial, 17ª ed. São Paulo: Atlas, 2015.

MENEZES, A. H. N. et al. Metodologia científica: teoria e aplicação na educação a distância. 1 ed. Petrolina: Universidade Federal do Vale do São Francisco, 2019.

MESQUITA, L. L. M. A contabilidade gerencial como mecanismo de gestão empresarial. Universidade Federal de Mato Grosso, Cuiabá, 2017.

MORAIS, R. A. C.; JÚNIOR, A. C. B. A importância da contabilidade gerencial para microempresas e empresas de pequeno porte. Revista de psicologia, v. 13, n. 43, p. 903-921, 2019.

NUNES, G. C. et al. Pesquisa científica: conceitos básicos. Id on Line Revista de Psicologia, v. 10, n. 29, p. 144-151, 2016.

PADOVEZE, C. L. Manual de contabilidade básica. Grupo Gen-Atlas, 2017.

PAOLESCHI, B. Estoques e armazenagem. 1ํㅡㄹ ed. São Paulo, 2014.

PEREIRA, S. et al. Metodologia da pesquisa científica. 1. ed. Santa Maria, RS: UFSM, NTE, 2018. 
POSSAMAI, C. G. Planejamento estratégico adotado como ferramenta de gestão: um estudo de caso em uma empresa comercial. Universidade do Extremo Sul Catarinense, UNESC, Criciúma, 2015.

RESSER, C. A.; PEREIRA, S. C. O papel do contador como gestor organizacional: percepções e análises da contabilidade gerencial. Revista Eletrônica de Ciências Contábeis, v. 7, n. 1, p. 260-278, 2018.

RIBEIRO, O. M. Contabilidade geral fácil. Saraiva Educação SA, 2017.

SCHIAVON, S. H. et al. Utilização de periódicos como referencial teórico nas dissertações e teses sobre a formação continuada de professores (2010-2014). Páginas de Educación, v. 8, n. 2, p. 158-171, 2015.

SEBRAE. Confira as diferenças entre micro empresa, pequena empresa e MEI. 2013. Disponível em: https://www.sebrae.com.br/sites/PortalSebrae/artigos/entendaas-diferencas-entre-microempresa-pequena-empresa-emei,03f5438af1c92410VgnVCM100000b272010aRCRD. Acesso em: 03 set. 2021.

SEBRAE. Tudo sobre ramos de atividades e como escolher o seu. 2019. Disponível em: https://www.sebrae.com.br/sites/PortalSebrae/artigos/artigoshome/ramos-deatividades,8ef89e665b182410VgnVCM100000b272010aRCRD. Acesso em 03 set. 2021.

SILVA, A. J. et al. Gestão financeira em empresas: um estudo sob a ótica de especialistas alagoanos. Revista de Gestão, Finanças e Contabilidade, v. 10, n. 3, 2020.

SILVA, D. S. et al. Análise de custos e sua importância na tomada de decisão em pequenas empresas do ramo alimentício: um estudo de caso. Revista Produção Industrial \& Serviços, v. 4, n. 2, p. 159-171, 2017. 
SOARES, M. O perfil do profissional contador e a importância da ética em sua formação. Revista Gestão em Conhecimento, v. 1, n. 1, 2021.

SOUSA, F. S. O; OLIVEIRA, A. M. B. A importância da ética para o profissional da contabilidade. ID on line Revista de psicologia, v. 13, n. 43, p. 295-309, 2019.

TACHIZAWA, T. Gestão com pessoas: uma abordagem aplicada às estratégias de negócios. Editora FGV, 2015.

ZANELLA, L. C. H. Metodologia de pesquisa. 2. ed. Florianópolis: Departamento de Ciências da Administração/ UFSC, 2013.

Enviado: Setembro, 2021.

Aprovado: Novembro, 2021. 